\title{
uventude, Religião e Espaço Público:
Exemplos "Bons para Pensar" tempos E SINAIS
}

Regina Novaes

Para minha querida amiga Santuza Cambraia Naves, a antropóloga da música, com imensa saudade.

As relações entre religião e política continuam delicadas. Em pleno século XXI, nessas alturas dos "tempos modernos", transformações sociais recentes se encarregam tanto de (re)produzir conhecidos distanciamentos e permanentes tensões quanto de produzir inéditas aproximações entre essas dimensões da vida social.

Com efeito, a dimensão religiosa tem resistido a se circunscrever à vida privada, ao foro íntimo e hoje ganha outros fôlegos não previstos na grande narrativa que separou religião e política, o público e o privado, magia e religião. $\mathrm{Na}$ geopolítica mundial, vertentes religiosas alimentam sectarismos, fundamentam embates políticos e econômicos. Ao mesmo tempo, e também pelo mundo afora, Estados laicos se relacionam com múltiplas expressões religiosas que adentram pelo campo da cultura e da política. Assim sendo, valores e símbolos religiosos têm frequentado o espaço público.

Nas atuais circunstâncias, é preciso sublinhar que a noção de espaço público, pensado como lugar de encontro (de divergências, disputas e negociações) entre sociedade e Estado, também vem se modificando. As demandas 
da sociedade atual não comportam hoje uma base única de representação cuja unidade poderia ser garantida por interesses comuns, corporativos ou de classe. Mudanças mundiais no mundo do trabalho (desemprego, flexibilização, terceirização, auto-emprego etc.) resultaram em descentralização das negociações. Neste "espaço público ampliado" evidenciam-se velhas e novas contradições, disputas entre variados atores, surgimento de novas demandas e de múltiplos centros de negociação de interesses. Com conteúdos, formatos, performances e rituais diversificados, indivíduos, grupos e instituições levam diferentes demandas ao espaço público onde são disputados recursos materiais e simbólicos.

Em sociedades cada vez mais policêntricas, as novas tecnologias de informação e comunicação também pesam na ampliação do espaço público no qual surgem inéditas maneiras de incidir. No decorrer desse processo histórico, sem estar sujeito a um poder soberano específico e às fronteiras geográficas de um país, também o "espaço público internacional" é "configurado pela geometria variável das relações entre Estados e atores globais" tais como as multinacionais, as religiões, os criadores culturais, os intelectuais e cosmopolitas globais (Calderón e Lechner 1998:22)

Dessa maneira, em diferentes territórios, atores religiosamente motivados se encontram com outros atores políticos - civis e secularizados - contribuindo para o aumento do estoque de ideias e de posicionamentos que alimentam o debate público nacional e internacionalmente. Assim sendo, valores culturais classificados como religiosos (e vice versa) e valores religiosos classificados como políticos (e vice-versa) se intercruzam no campo da convivência civil e chegam, até mesmo, a se incorporar nos projetos e ações de setores governamentais encarregados da formulação de políticas públicas.

Pode-se dizer, portanto, que hoje são muitos os usos (e abusos) políticos do conceito de cultura e, por decorrência, de diversidade cultural, onde também se inclui a dimensão religiosa. Não é difícil observar como, sobretudo em situações em que se explicitam disputas de poder e conflitos sociais, as ideias de "multiculturalismo" e "interculturalidade" são contraditoriamente acionadas. Por um lado, acionar a noção de "diversidade" pode significar produzir isolamentos estratégicos, mantendo culturas, grupos, identidades e religiões em seus "devidos lugares". Por outro lado, simultaneamente, em espaços de disputas democráticas, o "reconhecimento da diversidade" tem contribuído para aumentar o peso de valores e pertencimentos religiosos por meio de uma afirmação ética que prega "a paz e justiça" e evoca universais "direitos humanos".

No presente artigo, com o objetivo de refletir sobre tais questões, pretendo retomar informações de pesquisas, realizadas nos últimos dez anos, sobre determinados segmentos de jovens brasileiros que - de maneiras diversas - se fazem presentes no espaço público. A ideia é explorar as experiências desses jovens do ponto de vista de sua atuação na chamada "sociedade civil". Isto é, 
sem desconhecer as ambiguidades e sem minimizar o hiato existente entre as retóricas e as práticas do poder público, gostaria de explorar algumas das (re)apropriações da noção de diversidade cultural (e religiosa) entre jovens que se movem em espaços da ciência, cultura e da política.

\section{1 - Secularização e diversidade religiosa em um espaço de ciência}

Berger (2001) reconhece que o conceito de "secularização" contribuiu para a separar a religião da ciência e da política e, ao mesmo tempo, reconhece também que - no processo histórico - a secularização não atingiu com a mesma intensidade e da mesma forma todas as culturas, povos, nações, classes e grupos. Ou seja, seus efeitos são múltiplos e nem sempre convergentes.

Nesse mesmo texto, Berger faz uma intrigante referência às crenças que prevalecem no mundo acadêmico. $\mathrm{O}$ autor afirma que

existe uma subcultura internacional composta por pessoas de educação superior no modelo ocidental, em particular no campo das humanidades e das ciências sociais, que é de fato secularizada. Essa subcultura é o vetor principal de valores iluministas. Embora seus membros sejam relativamente poucos, são muito influentes, pois controlam instituições que definem 'oficialmente' a realidade, principalmente o sistema educacional, os meios de comunicação de massa e os níveis mais altos do sistema legal. São notadamente semelhantes em todo mundo atual (...) (idem:11).

Ou seja, trata-se de uma "cultura de elite globalizada" que tem "às vezes um choque cultural com o povo". Contudo, como se sabe, embora a aposta na secularização tenha estado na base da existência da "comunidade científica internacional", sendo uma espécie de denominador comum que une os "cientistas sociais secularizados", nem mesmo no espaço acadêmico se logrou a pretendida homogeneidade. Em vários países, cientistas sociais com vínculos religiosos se fizeram presentes em espaços legitimados de produção da antropologia e da sociologia da religião. Bourdieu (2004), no clássico artigo "Sociólogos da crença e as crenças de sociólogos", reconhece essa presença e aconselha que se abandone o jogo duplo com a teologia e que se faça a objetivação sem complacência de toda a crença religiosa.

Nessa mesma perspectiva, em um instigante trabalho sobre os "sociólogos da religião" no Brasil, Antonio Flávio Pierucci (1997) identificou três grupos. Um primeiro grupo é composto por "religiosos praticantes" que exercem competentemente a antropologia e a sociologia da religião, um segundo grupo de "religiosos praticantes/profissionais da religião" é composto por aqueles "que 
não sabem separar as esferas, não exercitam a vigilância epistemológica, fazem um produto híbrido e mal definido, que alegam ser antropologia ou sociologia da religião". Por fim, um terceiro grupo, menos numeroso e "puramente acadêmico", caracterizado como "profissionais da ciência".

Considerando o tempo histórico em que foram socializados os cientistas sociais aos quais se referem Berger, Bourdieu e Pierucci, talvez no esquema acima falte identificar um quarto grupo: aquele que é "puramente acadêmico" - sem vínculos com instituições religiosas - mas que não faz a "objetivação sem complacência" de sua inabalável crença na "secularização" como um "valor" para o estabelecimento das modernas sociedades republicanas, tal como foi formulado no início do século XX. Isto é, ao afirmar "o valor (de uma vertente) da ciência" eles também estariam deixando de lado a "vigilância epistemológica" na medida em que não consideram a historicidade da própria produção de classificações e conceitos no âmbito das ciências sociais.

Faz algum tempo que venho me perguntando como os ventos secularizantes se combinam com os "sinais dos tempos" pós-modernos na formação de jovens estudantes de ciências sociais. De fato, comecei a pesquisar as crenças religiosas entre estudantes de Ciências Sociais quando ofereci a disciplina "Ritual e Simbolismo", no Instituto de Filosofia e Ciências Sociais, o IFCS, da UFRJ. Como trabalho final de curso, uma parte dos alunos escolheu pesquisar rituais de distintas tradições religiosas. Em sala de aula, esses alunos justificaram suas escolhas pela visibilidade de certas crenças, ou por ser a religião dos pais, ou por se tratar da religião em que foram criados. Ou, ainda, e sem os constrangimentos impostos aos estudantes de ciências sociais de minha geração, para compreender "antropologicamente" suas próprias buscas ou pertencimentos religiosos.

Um texto discutido no curso foi usado para legitimar aquelas escolhas. Era um texto de Roberto Cardoso de Oliveira (1998) que discorria sobre os diferentes paradigmas da antropologia, valorizando justamente o mais recente: o "interpretativismo". Neste paradigma, que o autor classifica como "hermenêutico", a subjetividade, liberada da coerção da "objetividade", toma sua forma socializada, assumindo-se como "intersubjetividade". O que justificaria ao antropólogo estudar algo que não the é indiferente como sua religião ou sua religiosidade. Naquela ocasião, diferentes estudos dos alunos revelaram conexões entre aquele espaço universitário laico e o campo religioso brasileiro (no qual já se detectava a diminuição do catolicismo, o crescimento do pentecostalismo e a emergência de um conjunto de alternativas místico-esotéricas, também chamadas de "nova era").

Depois disso fiz duas pesquisas quantitativas com alunos do IFCS. Na primeira, em 1994, obtivemos 56\% de declarações afirmativas para a pergunta "você tem religião?" (católicos 33\%, evangélicos 11\%, espíritas 8\% e adeptos do candomblé 4\%) e 44\% de "sem religião". Outras perguntas e outras abordagens 
complementares permitiram captar trajetórias e itinerários nos quais se verificaram alternâncias, mudanças, combinações entre crenças religiosas. Recordo alguns exemplos: um aluno ateu que se tornou católico quando se engajou como agente pastoral negro (APN); um católico não-praticante que no IFCS se tornou ateu "petista" mas depois, em contato com outros alunos, se converteu ao pentecostalismo da Assembleia de Deus, atuando na "renovação" de sua igreja; um católico que combinava sua militância nas "progressistas" Comunidades Eclesiais de Base (CEBs) com a frequência em missas da Renovação Carismática Católica, então considerada como reação conservadora da Igreja Católica. Diferentes combinações entre tradições afro-brasileiras, religiões orientais e esoterismo também se davam a conhecer nas conversas, nos adereços e nos livros sagrados que se faziam visíveis no IFCS dos anos de 1990.

$\mathrm{Na}$ segunda pesquisa, quatro anos depois ${ }^{2}$, apenas 34\% dos alunos entrevistados disseram ter uma religião e $64 \%$ se declararam "sem religião". Em uma primeira leitura parecia que enfim os ventos secularizantes estavam soprando mais fortemente naquele espaço de ciência. No entanto, o cruzamento entre diferentes respostas, assim como as entrevistas complementares, revelaram que o número de ateus não crescia em relação à pesquisa anterior. Ou seja, entre os $64 \%$ dos "sem religião", apenas $9,1 \%$ se declaram ateus enquanto $39,8 \%$ escolheram a alternativa "sem religião institucional". Nas respostas abertas, uma parcela considerável dos entrevistados se declaravam "em trânsito", entre escolhas religiosas. Outros, indicando uma aproximação entre técnicas de autoconhecimento, expedientes terapêuticos e crenças religiosas, diziam dispensar a mediação institucional em prol de uma síntese pessoal. Muitas respostas apontavam para combinações inéditas e para novos sincretismos. Dessa maneira, recompondo percursos e trajetórias religiosas foi possível identificar pontos de partida, interregnos e pontos de chegada entre os quais os jovens se moviam na dimensão religiosa de suas vidas.

Lembrando que o Censo de 2000 do IBGE também apontava para o crescimento dos "sem religião", particularmente no Rio de Janeiro (15,5\%), para analisar os resultados dessa pesquisa explorei a noção de "experiência geracional". Além de viverem em um tempo de intensa experimentação de novas tecnologias de informação e comunicação virtual, os entrevistados, alunos do IFCS, faziam parte de uma geração marcada por processos de globalização que ampliaram suas incertezas tanto diante de um mercado de trabalho restritivo e mutante quanto frente às distintas formas de violência física e simbólica às quais estavam submetidos em uma cidade marcada pela presença do tráfico de drogas e pela corrupção policial. Nesse contexto, em comparação com as gerações anteriores, tanto os "problemas sociais" (aos quais dirigir perguntas sociológicas e construir objetos de investigação), quanto os elementos socioculturais disponíveis para a construção do ethos de cientista social não eram os mesmos. 
Ou seja, naquele finalzinho de século, o curso de Ciências Sociais não era mais um espaço de socialização onde se produziam estratégias de ocultamento de "crenças não científicas" e onde se projetava um almejado "perfil de aluno" sem pertencimento religioso, tal como constava em minha memória (certamente seletiva) de ex-aluna daquele mesmo estabelecimento de ensino. Além disso, também questionando o percurso de outras gerações - que via de regra obedecia a linear sequência entre a religião de família $>>>0$ ingresso no curso de ciências sociais $>>>$ "secularização pessoal"/ateísmo $>>>$ engajamento político - a pesquisa revelou outra inesperada correlação: situados entre os "sem religião", os alunos que se declaram ateus eram os que tinham menores intenções e práticas de engajamento político. Portanto, idas, vindas e novas buscas na religião e na participação política pareciam indicar outros parâmetros de cognição e ação.

Assim sendo, as informações obtidas indicavam que, também no âmbito das ciências sociais, cada experiência geracional é inédita. Historicamente definidas, mostravam-se mutáveis as relações entre: as regras do fazer acadêmico; as formas de incidência no espaço público e os significados de pertencimentos e buscas religiosas. Para os jovens cientistas sociais formados a partir daqueles anos, ampliavam-se as referências geográficas e bibliográficas e, também, modificavam-se as perguntas e os objetos de estudo construídos em torno da dimensão religiosa da vida social.

Desse ângulo, naquele momento da história, mesmo as quatro possibilidades de classificação dos "sociólogos da religião" acima sugeridas já se mostram insuficientes e outros jogos de posições e oposições precisam ser identificados. Por exemplo, para definir hoje o "puramente acadêmico", seria necessário relacionar vários tipos de crenças e pertencimentos com as distintas maneiras de exercer a necessária "objetivação reflexiva" e a "vigilância epistemológica". Para cada uma das posições, que se apresentam neste campo de possibilidades, haveríamos de indagar como valores iluministas são reafirmados, complementados ou negados entre sociólogos e antropólogos que, mutuamente, reconhecem-se aqui e na comunidade acadêmica internacional.

De fato, tornar a religião um objeto de investigação sempre é se submeter a um considerável esforço de objetivação reflexiva. Isto, não só porque é necessário assumir e refletir sobre a própria pertença ou crença religiosa, caso haja. Mas, também, porque é preciso não subestimar a necessidade de objetivação - não menos dolorosa - dos conceitos (e preconceitos acadêmicos) que habitam o mundo ao qual os cientistas sociais pertencem.

A "secularização" (ideia, acontecimento histórico e conceito sociológico) teve grande importância para reinventar o mundo em um momento histórico de afirmação do Estado "de direito", laico, sobretudo para limitar o poder políticoreligioso de Roma. Passados muitos anos, já é hora de investigar como e quanto a narrativa da secularização foi (re)apropriada, por diferentes atores, no curso 
da história, na constituição diferenciada dos Estados-nacionais (Giumbelli 2006). Porém, hoje, com a intensificação da globalização e tensionamento das fronteiras nacionais, é preciso indagar que outros conceitos ocupam lugares semelhantes na configuração do espaço público.

A noção de "diversidade cultural" (conceito antropológico e suas diferentes apropriações bem mais recentes), tal como ocorreu com o conceito de secularização, também transpõe fronteiras acadêmicas e "espirala pela sociedade", para usar uma conhecida expressão de Giddens (1990). Este "efeito teoria" usando agora uma expressão cunhada por Pierre Bourdieu (2004) - também não é sem consequências para o que acontece no interior e, também, no exterior do mundo acadêmico. Vejamos alguns exemplos.

\section{2 - Religiosidade e política em espaços da chamada cultura hip hop}

O rap, o break e o grafite compõem a trilogia da cultura Hip Hop. No Brasil nas favelas e conjuntos habitacionais, nas chamadas "periferias", desde os anos de 1990, destacam-se grupos culturais que, através do movimento hip hop, denunciam a violência física e simbólica presente na sociedade e clamam pela "união dos manos".

Cada manifestação de rap (com seus DJs e MCs) é um resultado singular do encontro de elementos e informações locais e globais ${ }^{3}$. O rap é ritmo e poesia. O ritmo valoriza a palavra que, por sua vez, produz a atitude. A batida, a palavra e atitude se somam para disseminar uma "visão crítica" frente às desigualdades sociais, ao preconceito racial, a precariedade das ações do Estado, a corrupção e a truculência policial.

Referências e símbolos socialmente reconhecidos como religiosos não estão presentes em todas suas letras, mas nelas são bastante recorrentes. Escrevendo sobre letras de rap que continham referências religiosas, propus (Novaes 2003) um continuum no qual em um extremo teríamos o pertencimento confessional evangélico, o chamado "rap gospel". Na zona intermediária, estavam as expressões sincréticas entre as quais destacam-se aquelas que evocam Jesus Cristo e os Orixás, remetendo-nos, sobretudo, à nossa tradição cultural de duplo pertencimento ao catolicismo e às religiões de matriz africana. Assim como, mais recentemente, outras misturas que incluem referências orientais, da tradição budista ou hinduísta. E, finalmente, no outro extremo, estariam letras de "raps feitos de salmos" nos quais se fala diretamente de (ou com) Deus interpretando livremente a Bíblia, dispensando pertencimentos e mediações institucionais. Vejamos alguns elementos dessa classificação (que, como toda classificação, deve ser vista como provisória).

O rap Gospel expressa o segmentado mundo evangélico no qual o "pertencimento denominacional" sempre foi visto como uma característica 
constitutiva. Os grupos que foram observados na pesquisa combinam duas missões: a do movimento hip hop, que através da palavra cantada faz denúncias sociais para "conscientizar" os jovens da periferia, e a missão religiosa que, através de diferentes beats e rimas ${ }^{4}$, propõe a adesão ao evangelho e um estilo de vida cristão.

Seguem alguns exemplos. O grupo Provérbio X é de Brasília e seu objetivo maior se resume na seguinte frase "Ide e Pregai o evangelho". O grupo Alternativa C "prega a evangelização dos povos, a união, paz e crescimento sem esquecer os problemas da sociedade". O Eclesiastes, de Carapicuíba - São Paulo, apresentase em rádios comunitárias e em programas de rap nacional, fazendo a "evangelização dos que os escutam". Apocalipse 16 também é composto de "rappers" paulistas que dizem combinar "crítica social" com a evangelização onipresente em suas letras. Além dos grupos, existem também os DJs que atuam individualmente. Este é o caso do DJ ALPISTE, que diz fazer "música com consciência cristã" e que espera encontrar no hip hop "uma fórmula mais segura para encontrar a paz" (Novaes 2003).

Em seguida, no mesmo artigo já mencionado, vinha o rap sincrético. A referência ao "sincretismo" buscava passar longe das definições que o remetem a desvios da religião cristã pura, sem misturas e confusões rituais ou doutrinárias. Buscava-se fugir de correlação de sincretismo e "falta" (de capacidade das Igrejas de bem evangelizar e dos fiéis de bem compreender dogmas e doutrinas). A ideia era pensar o "fenômeno do sincretismo" enquanto um processo incessante de apropriação e troca cultural (Sanchis 2001), atualmente potencializado pela circulação mais veloz de informações e símbolos religiosos.

Como exemplo de "rap sincrético", na ocasião, recorri a Thaíde e DJ Hum, considerados os "irmãos mais velhos" do Hip Hop brasileiro. Na letra denominada Sabe quem eu sou?, eles dizem: "Evoco espíritos no atabaque/ mas também preciso da benção do padre". O "duplo pertencimento" - ao catolicismo e às religiões de matriz africana - já foi bastante estudado no Brasil.

Na mesma linha, podemos citar o grupo O Rappa, do Rio de Janeiro, que em uma de suas letras também evoca Cristo e Oxalá. Descrevendo a "vida no morro" e suas relações tensas com a polícia, afirmando que "o próprio Cristo era mulato", a letra termina dizendo: "Se eu me salvei, foi pela fé/Minha fé é minha cultura /Minha fé, minha fé/É meu jogo de cintura, minha fé".

A Polícia, Deus e os Orixás também estão presentes em um rap do grupo Juventude Sangrenta de Caruaru, Pernambuco, que diz assim: "Eu tenho Deus comigo para me guardar, eu tenho as forças dos meus Orixás, por aqui não vou parar, vou te explicar do trabalho da Polícia Militar, ainda desses caras eu tenho muito a falar".

Mas, sendo a violência bastante recorrente nas letras do "rap sincrético", neste espaço também vale introduzir informações estatísticas. A letra do rap a Fórmula Mágica da Paz, do grupo Racionais MCs, exemplifica bem a questão: 
"Agradeço a Deus e aos orixás. Cheguei aos 27 anos, tá ligado? Agradeço a Deus, agradeço a Deus. Cheguei aos 27 anos contrariando as estatísticas". Dados do IBGE são citados demonstrando o entrelaçamento de diferentes domínios de saber da sociedade.

Também como exemplo de ampliação de "matéria prima" para alimentar processos de convivência sincrética entre jovens artistas das chamadas periferias brasileiras, podemos citar o filme documentário intitulado Favela Rising - dirigido por Jeff Zimbalist e Matt Mochary. Ao retratar a realidade das favelas do Rio de Janeiro, o documentário destaca a trajetória de Anderson, um dos integrantes da banda Afro Reggae. A morte rondou de perto a vida de Anderson e o documentário mostra como diferentes crenças e rituais se combinaram em busca de sua cura, reinserção pessoal e profissional. Na luta por essa vida, tornam-se aliados os santos católicos, os orixás, as mães de santo e o deus Shiva da tradição hindu. Nessa banda, em que o "afro" é exibido na raiz e no próprio nome, Shiva, deus da transformação e da reconstrução, tornou-se uma importante "referência espiritual" para "disputar com o tráfico de drogas, transformar e reconstruir", trajetórias juvenis por meio de atividades culturais ${ }^{5}$.

Depois de caracterizar o rap gospel e o rap sincrético, chegamos ao "rap feito de salmos". Suas letras foram consideradas distintas do "rap gospel" na medida em que não se vinculavam a uma missão ou denominações evangélicas. E, por outro lado, foram consideradas distintas do rap sincrético pois não faziam referências aos santos, aos orixás, à "benção do padre" ou a outras autoridades religiosas. Caracterizavam-se por leituras inéditas da Bíblia relacionando livremente seus salmos e versículos com os dramas sociais que pontuam suas vivências cotidianas.

As letras classificadas como "Rap feito de salmos" introduziam a Bíblia como matéria prima poética. A proliferação de edições baratas da Bíblia, o seu alcance via internet, o trabalho religioso de grupos evangélicos com visibilidade crescente nas praças, trens e a cada esquina favoreceram, naquele início de milênio, o acesso à Bíblia e sua apropriação pelos rappers. Estas letras exploraram a fragilidade das fronteiras que separam o sagrado e o profano. Seguem alguns exemplos.

O CD dos Racionais, Sobrevivendo no Inferno, vendeu um milhão de cópias, e em sua capa aparece escrito: "Refrigere minha alma e guia-me pelo caminho da justiça" - Livro dos Salmos, Salmo 23, cap.3". Na contracapa outra frase bíblica: Salmo 23, cap. 4 "e mesmo que eu ande no vale das sombras e da morte, não temerei mal algum porque tu estás comigo" (Novaes 2003).

Na vinheta falada na faixa "Gênesis", do mesmo CD, pode-se ouvir "Deus fez o mar, as árvores, as crianças e o amor/O homem lhe deu favela, o crack, as armas, a bebida, as putas/Eu tenho a Bíblia e a pistola automática. Estou tentando sair desse inferno". 
Na faixa Diário de um detento, ouve-se:

(...) O ser humano é descartável no Brasil/como Modess usado ou Bombril (...)Rá-tá-tá-tá, sangue jorra como água/do ouvido, boca e nariz/O senhor é meu pastor/perdoai o que seu filho fez/morreu de bruços no Salmo 23/Sem padre, sem repórter, sem arma, sem socorro/ Vai pegar HIV na boca do cachorro....

Em outra faixa, denominada Capítulo 4, Versículo 3, esclarece-se:

60\% dos jovens de periferia, sem antecedentes criminais, já sofreram violência policial; A cada 4 pessoas mortas pela polícia, 3 são negras; Nas universidades brasileiras, apenas 2\% dos alunos são negros; A cada 4 horas um jovem negro morre violentamente em São Paulo; Aqui quem fala é Primo Preto, mais um sobrevivente.

Na imprensa os Racionais foram chamados de "Canudos Urbanos" e, entre estudiosos progressistas, indagou-se se a presença de referências religiosas, em letras de forte conteúdo social e político, poderia ser considerada uma "regressão a Deus", um expediente conformista, por si mesmo como incongruente com o mundo da política Porém, a meu ver, para além da grande importância que Canudos e outros movimentos messiânicos tiveram em nossa história, a ideia de "regressão à Deus", que supõe uma evolução linear entre percepção religiosa e consciência política, não contribuía para explicar a "produção cultural" daqueles jovens inconformados moradores das favelas e conjuntos habitacionais privatizados pelo tráfico e submetidos à violência e corrupção policial. Com efeito, as referências bíblicas, com a força das ideias "fora do lugar", tanto potencializam a mensagem política imediata que estes rappers queriam transmitir, quanto expressam na busca de Deus um "sentido" para suportar as "mazelas da sociedade". Isso sem ordem de prioridade entre ação e cognição, representações e práticas.

Nesse cenário, classificar as letras destes raps tornou-se um exercício de relativização de pares de oposição e esquemas explicativos forjados em outros tempos e para outras sociedades, simples ou complexas. De fato, em suas letras, gírias, palavrões e estatísticas - ao lado de referências bíblicas - produziram uma rica e impactante complementaridade entre o sagrado e o profano, o erudito e o popular, o sabido e o profético.

Passados esses anos, ao retomar essa classificação creio ser importante atentar para outras mudanças no campo religioso, particularmente no meio evangélico. O continuum que classifica as letras entre o rap gospel, sincrético ou "feito de salmos", já não dá conta do conjunto das letras que tenho analisado mais recentemente. Naquele momento, o rap "feito de salmos", caracterizado 
pela ampliação do acesso à Bíblia, conectava-se com uma novidade na época, a saber, o aumento dos "religiosos sem religião". O rap gospel, por sua vez, se caracterizava por seus vínculos a denominações pré-existentes ou constantemente criadas no mundo evangélico pentecostal. Hoje essas fronteiras ficaram cada vez menos nítidas.

O pertencimento exclusivo e a assiduidade aos cultos já não podem ser vistos como o principal denominador comum do "ser crente", do "ser protestante", do "ser pentecostal", "ser evangélico". Existe hoje um segmento de jovens que pode ser classificado como "evangélico genérico" terem encontrado um mundo em que a equação ser católico/ser brasileiro já estava desnaturalizada, também já cresceram naturalizando a presença de múltiplas igrejas evangélicas pelos quatro cantos do país, das cidades e em suas periferias. Se é verdade que tem crescido aquela "população flutuante", tal como caracterizada por Almeida (2006), é nessa paisagem que foram socializados os jovens das diferentes "periferias" que tenho pesquisado.

À primeira vista os "evangélicos genéricos" guardariam alguma semelhança com os "católicos não praticantes" na medida em que ambos se definiriam simplesmente como "evangélicos" ou como "católicos" e ambos não são encontrados regularmente nos cultos e missas. Contudo, a comparação é simplificadora porque deixa de lado o peso da histórica hegemonia católica na sociedade brasileira e, assim, não leva em conta as características próprias das vertentes cristãs não católicas que, como "minorias religiosas", foram provocando rupturas e conquistando adesões nesse país tantas vezes definido por suas capacidades sincréticas.

Deixando para outra ocasião as necessárias - mas complexas comparações $^{10}$, nos limites deste texto, o importante é levantar a hipótese de que essa possibilidade - ser evangélico genérico - deve ser levada em conta nas avaliações do lugar do pertencimento religioso na configuração do espaço público.

Afinal, trata-se também de uma possibilidade que modifica o peso da autoridade religiosa em decisões que dizem respeito à participação social. Como tem sido observado, há situações em que jovens deixam de participar de atividades artísticas, ligadas à cultura afro-brasileira, em ONGs e Projetos governamentais, por conta de proibições de seus pastores. Assim como há relatos de pastores que criam obstáculos para a inserção de jovens em espaços em que se valoriza a diversidade sexual ou onde se questiona a proibição do aborto. Alguns desistem de "participar" e outros mudam de pastor ou de denominação. Nesse cenário, definir-se apenas como "evangélicos" pode ser também uma outra maneira para contornar conflitos e proibições. Reafirmando elos com este universo religioso, mas não se sentindo presos a denominações, jovens evangélicos (genéricos) inserem mais uma possibilidade no repertório dos modos de estar e se movimentar no espaço público. 
Desse ângulo, esse "evangélico genérico" não poderia ser visto apenas um consumidor de bens ou serviços atualmente disponibilizados na mídia e em agencias religiosas reconhecidas pelo "estilo evangélico". Esta explicação parece não dar conta dos aspectos simbólicos e da produção de sentidos presentes tanto no chamado "consumo de bens religiosos" quanto nas maneiras de se apresentar e se envolver em disputas e criar alianças no espaço público. Nesse sentido, voltando ao interior do movimento hip hop, é possível perceber que ali se gestou uma específica forma de confluência entre religiões que se antagonizam na sociedade.

Como se sabe, os evangélicos demonizam as religiões afro-brasileiras e, ao mesmo tempo, o movimento negro se preocupa com as repercussões negativas do avanço evangélico sobre manifestações da "cultura afro-brasileira" nas escolas e nas comunidades. Certamente, esses pontos de conflito, sempre latentes, não devem estar ausentes no interior do movimento hip hop. Porém, e não por acaso, desde o ano de 2001, o Prêmio Hutus, considerado como o maior evento deste estilo do Brasil, incluiu o rap gospel como uma das categorias concorrentes ${ }^{11}$.

Em outras categorias disputam raps e personalidades que podem (ou não) sincreticamente evocar seus orixás, seus santos, suas igrejas e terreiros, que podem (ou não) utilizar a Bíblia, ou outros livros sagrados, sem pertencimento ou controle institucional. Já o lugar de destaque do rap gospel naquele espaço de afirmação identitária de "jovens da periferia" revela o reconhecimento de uma categoria advinda do mundo da religião (gospel) e, ao mesmo tempo, um expediente de neutralização das disputas mais acirradas que se dão no campo religioso. Dessa maneira - na prática - no interior do hip hop amplia-se o escopo da assim chamada "cultura afro-brasileira", via de regra identificada apenas com as religiões de matriz africana. "Ser do rap" evoca "atitude" e esse elo identitário comporta/suporta a diversidade religiosa.

Nutrindo esse imaginário político específico - cujo slogan poderia ser "periferia é periferia em qualquer lugar", como afirmou Mano Brown - essa narrativa de "unidade na diversidade" foi ganhando repercussões no espaço público. O que ficou evidente, em janeiro de 2003, em Porto Alegre, Rio Grande do Sul, durante o Fórum Social Mundial quando rappers, vindos de diferentes estados do Brasil, se reuniram para "se organizar". Depois, ano após ano, representantes do "movimento hip hop" foram sendo cada vez mais requisitados em outras edições do FSM e em outros eventos similares. Retomaremos esse ponto mais adiante.

\section{3 - Fóruns, Acampamentos, Conselhos, Marchas: moedas (de uso e de troca) na religião e na política}

O mundo está marcado pelos processos que a globalização promove. Como já foi dito, nem o todo, nem todos estão globalizados, mas processos e redes 
globais afetam o todo e a todos. Nesse contexto, visando incidir nas disputas do "espaço público internacional”, nasceu o Fórum Social Mundial (FSM).

Precedido por conexões internacionais nos encontros de Seatle, Gênova, nas ações "contra-cúpulas", na Ação Global dos Povos, nos Encuentros Intergalácticos dos Zapatistas, o FSM se propôs a desenvolver um processo

catalisador dos esforços e lutas acumuladas pelos movimentos sociais, sindicais, eclesiásticos e camponeses, de organizações civis e setores políticos populares a nível global como resistência ao modelo capitalista, enfrentamento ao neoliberalismo, em oposição ao Fórum Econômico de Davos (reunião dos oito países mais ricos do mundo) ${ }^{12}$.

No âmbito do FSM, em 2001, surgiu o Acampamento Internacional da Juventude (AIJ). Isso porque, por um lado, havia a necessidade de oferecer alojamento em Porto Alegre para os jovens que iriam participar do FSM e, por outro lado, entre jovens militantes havia a intenção de juntar forças para inserir a temática da juventude nas pautas propostas pelo Fórum (Fischer et alli 2007).

No primeiro ano, segundo memória dos organizadores do Acampamento (idem), o acesso ao Acampamento esteve subordinado a inscrições das organizações da sociedade civil às quais os jovens estivessem ligados. Mas, a partir do $2^{\circ}$ Acampamento, já criado um "Comitê Organizador da Juventude", evitando uma lógica de organização verticalizada, que prevalece no mundo da política, chegou-se a uma proposta mais horizontal que, além de representações de grupos, movimentos e organizações conhecidas, acolhesse também indivíduos e outros tipos de grupos até então considerados "não políticos".

No terceiro ano, ganhou força a ideia de fazer do Acampamento um "espaço plural e autogestionado". Como diz André Mombach um dos jovens organizadores: "Em 2003 soubemos fazer da diversidade a nossa maior força" Segundo descrição de Fischer et elli (idem), nos primeiros anos no Acampamento "destacavam-se jovens ligados aos movimentos internacionais anticapitalistas, movimentos sociais, estudantil e independentes, juventudes partidárias, juventudes ligadas a pastorais e igrejas, grupos e expressões culturais". A descrição dos anos seguintes é menos concisa: lá estavam

intelectuais, militantes, poetas, loucos, mochileiros, turistas e curiosos, os estudantes universitários, os festeiros, os engajados, os artistas, os místicos, 'pastoralistas' e religiosos, os jovens da periferia, do HipHop, os meninos e meninas de rua, os rebeldes, os punks e anarquistas (idem:26).

Dessa maneira, foram se intensificando as situações de convivência entre 
os tradicionais documentos e panfletos políticos e os rituais místicos, cantos, celebrações, manifestações culturais, sons de vários estilos e modalidades. Ao por do sol, nas margens do Rio Guaíba, as cerimônias místicas/políticas contaram com a presença significativa de jovens não só de pastorais engajadas, católicas ou evangélicas, mas também de religiões de matriz afro-brasileira, orientais e esotéricas.

Certamente, no decorrer dos anos, no Acampamento, surgiram conflitos internos e externos que merecem ser conhecidos e analisados ${ }^{14}$. Porém, também chama a atenção o seu modo de funcionamento, organização e gestão, com sistemas de segurança, alimentação, comércio solidário, espaços bioconstruídos e plano diretor de ocupação dos espaços. Também o ideário ecológico e a bandeira por software e hardware livre foram ganhando crescente destaque nas edições do Acampamento Internacional da Juventude.

Pesquisadores (Fischer et elli 2007), estudando a edição de 2005 do Acampamento Internacional da Juventude, destacam alguns espaços pelos quais os jovens circulavam. O Espaço Lògún Ede onde ganhou visibilidade a discussão da temática sobre homossexualidade e diversidade sexual, sexismo e fundamentalismo. O Espaço Ernesto Che Guevara voltado para discussão e aplicação de práticas alternativas de saúde e construção de novas políticas nesta área. A Cidade Hip-Hop para congregar rappers vindos de todo o país. A Tenda Kairós e o Espaço Interreligioso surgiram para abrigar iniciativas de diálogo e vivências inter-religiosas. Ou seja, os espaços religiosamente motivados ganhavam sentido justamente por estarem ao lado de outros com outras motivações ou causas.

Naquele contexto, a quem interessaria demarcar as fronteiras entre manifestações religiosas e políticas? De fato, no Fórum Social Mundial e no Acampamento Internacional da Juventude, a diversidade cultural tornou-se uma indispensável moeda política. A eficácia desta moeda aumentava na medida em que, naquele espaço, tornava-se possível - "sem pudores ou ocultações" (Pace 1997) - relativizar as clássicas definições que separam o religioso e o político. A categoria "diversidade" se tornou assim um amálgama essencial para possibilitar a existência do evento e garantir suas repercussões no espaço público. Entre as repercussões da experiência do Acampamento Internacional da Juventude - na visão de vários jovens entrevistados - tem sido contabilizada a criação, em 2005, da Política de Juventude, e mais particularmente do Conselho Nacional de Juventude (Conjuve).

Certamente existem muitos outros fatores que determinaram a criação da chamada Política Nacional de Juventude. Contudo, é possível afirmar que a exibição da "diversidade de grupos juvenis" durante as edições do Fórum Social Mundial, em Porto Alegre, teve repercussões na composição do Conjuve ${ }^{15}$. Em sua primeira composição, em 2005, além das representações do movimento estudantil e de jovens sindicalistas, foram convidados para compor o Conjuve: 
representantes do movimento Hip hop, jovens feministas e movimentos LBGT, assim como movimentos e grupos católicos, evangélicos, entre outros. Com o passar dos anos, em todas eleições para o Conjuve, para compor a "representação dos grupos religiosos", concorrem diversos grupos ${ }^{16}$. Assim, no âmbito do Conselho Nacional da Juventude, e também durante as duas edições da Conferência Nacional de Políticas Públicas de Juventude, a dimensão religiosa tem motivado participação de jovens na busca de "direitos dos jovens".

Nos espaços onde se demanda "Políticas Públicas de Juventude" encontramse jovens das Pastorais de Juventude Católica e dos grupos evangélicos de diferentes denominações e movimentos (como a Rede FALE e Aliança Bíblica Universitária), movimentos de jovens negros que reavivam referências religiosas de matriz africana (como do movimento denominado "Povos dos Terreiros", grupos de Hip Hop, coletivos de juventude negra), jovens de diferentes grupos étnicos que reivindicam direitos acionando cosmologias religiosas (tais como povos indígenas e ciganos); jovens que destacam a espiritualidade no seu engajamento em lutas ambientalistas; jovens que participam de redes e movimentos ecumênicos e inter-religiosos que se envolvem em lutas contra a violência e pela paz. No Conselho e nas Conferências de Juventude - duas modalidades previstas no modelo da almejada democracia participativa - jovens, religiosamente motivados, são vistos como parte da "sociedade civil organizada".

Por outro lado, é importante sublinhar ainda, o papel das novas tecnologias de informação e comunicação na própria caracterização de "sociedade civil". Certamente, as chamadas TICs podem (re)produzir as mais severas formas de desigualdades sociais, segregação, individualismo e consumismo. Mas, também, têm produzido expedientes que favorecem a comunicação e a identificação entre jovens, gerando coletivos virtuais, quebrando isolamentos, ampliando as possibilidades de ações e disseminação de causas sociais e modificando as relações entre elas.

Vejamos um exemplo. Recentemente, no dia 26 de maio de 2012, vários jornais anunciaram a segunda edição da "Marcha das Vadias" em várias cidades do Brasil. Para quem não sabe, o movimento mundial intitulado "Slut Walk" começou em 2011, após um oficial da polícia de Toronto, no Canadá, dizer que, para evitar estupros, as mulheres deviam deixar de "se vestir como vadias". O movimento mobilizou segmentos juvenis e se espraiou via internet. Em seus protestos contra o machismo as mulheres usam roupas provocantes e criam performances engraçadas e irreverentes.

Recentemente, ao observar a "Marcha das Vadias" em Copacabana no Rio de Janeiro pude também observar, naquele espaço de "unidade na diversidade", consideráveis espaços para a heterogeneidade. No momento em que um grupo gritava slogans a favor do aborto em frente a uma Igreja Católica, não pude deixar de observar algumas jovens que se apresentavam como da 
"Comunidade Betel" do Rio de Janeiro ${ }^{17}$ - e carregavam cartazes dizendo "sou cristã e sou lésbica, pela diversidade sexual" -, não se aproximaram da Igreja Católica. Não sei se elas ficaram esperando porque estavam cansadas, se não quiseram se aproximar da Igreja Católica por questões religiosas ou por tática política de evitar provocações ou se era a palavra de ordem a favor do aborto que justificava esta espera quase que em separado do grupo maior. Só sei que quando a Marcha seguiu até a Delegacia de Polícia, como estava na programação distribuída, elas se reincorporaram à Marcha. Não me senti à vontade para perguntar. Mas esse exemplo, que expõe a conhecida segmentação evangélica, também demonstra diferenças que não são anuladas no interior de espaços de participação civil, particularmente quando essa participação é religiosamente motivada.

E essa questão nos leva ao controverso tema da "identidade". Pesquisas recentes têm demonstrado que, em suas atuações no espaço público, os jovens somam "causas", sobrepondo diferentes identidades. Múltiplas causas e experiências de discriminação podem se somar na vida de um mesmo jovem (ser jovem, ser negro, ser favelado, ser homossexual, ser mulher, ser lésbica e "ser cristã"...). A predominância de uma identidade sobre outra ou a combinação de identidades e causas não acontece em abstrato, mas em processos sociais e trajetórias individuais concretas. Daí a necessidade de evitar esquemas empobrecedores que se ancoram em substantivação de identidades como se fossem únicas e fixas.

Um outro exemplo. Dessa vez para ilustrar o uso das ideias de diversidade e identidade na seara da Igreja Católica. Recentemente, no jornal O Globo, uma notícia na página 3, chamou minha atenção. A notícia reproduzia o cartaz do grupo Gays Cristãos, que contém: a) uma ovelha cor de rosa como o símbolo do grupo; b) uma frase em letras maiores: "o amor de Cristo nos uniu"; c) outra frase com letras menores: "gays na Igreja Católica"; c) a logomarca do grupo, no canto esquerdo, uma espécie de cruz estilizada com os dizeres "diversidade católica". Segundo a colunista: seus integrantes se definem como "leigos católicos que entendem viver duas identidades aparentemente antagônicas: ser católico e gay, incluindo a diversidade sexual". O primeiro encontro, semana passada, marcou o inicio de uma série de reuniões para "unir católicos em comunhão com o mundo GLS" (O Globo, 9 de junho, 2012).

Nessas circunstâncias, o que vem a ser diversidade católica? Não tenho elementos para responder a essa pergunta. Mas, pela maneira que a expressão foi usada na logomarca do grupo, fica claro que se trata de uma moeda simbólica que tem valor nos embates, internos e externos à Igreja Católica. Tanto nesse caso, no qual se busca "unir católicos em comunhão com o mundo GLS", como em outros exemplos acima citados, trata-se de investigar por que, como e em quais circunstâncias do debate público as identidades religiosas são naturalizadas e passam desapercebidas, ou são ocultadas ou acionadas. 


\section{4 - Entre jovens mobilizados: o "mantra" e o "direito" à diversidade}

Podemos agora indagar sobre o atual estado do pluralismo religioso na sociedade brasileira. É verdade que nos dados censitários o pluralismo é pouco evidente. Nas estatísticas prevalecem majoritariamente as religiões cristãs (primeiramente católica e, em segundo lugar, evangélica). Também é verdade que em várias situações são (re)confirmados conhecidas hierarquias do campo religioso brasileiro.

Por exemplo, no que diz respeito ao estabelecimento do calendário cívico, a (ainda considerável) hegemonia católica logra estabelecer novos feriados e a emergente influência evangélica chega no máximo (até o presente momento) a estabelecer dias comemorativos (Pitrez 2012). Já as decisões tomadas, no estado do Rio de Janeiro, sobre o ensino religioso nas escolas públicas fizeram confluir interesses católicos e evangélicos (Giumbelli e Carneiro 2004) submetendo os interesses de outras religiões. Por outro lado, quando estão em jogo definições sobre o patrimônio cultural brasileiro, os evangélicos é que saem de cena. Segundo Clara Mafra, enquanto agentes de outras religiões, em especial, católicos e afrobrasileiros, investiram em negociações e subordinações do "religioso" ao "cultural" - como estratégia de ganho em termos de reconhecimento e de legitimidade social via inclusão de si no leque da diversidade cultural que compõe a nação - "os evangélicos tendem a desenvolver relações externalistas com as políticas culturais propostas pelo Estado e por agências transnacionais de aporte secular" (Mafra 2011).

Nesses exemplos podemos perceber que o "leque da diversidade cultural que compõe a nação" ganha e/ou perde visibilidade, legalidade e apoio do poder público de acordo com diferentes disputas e alianças no campo religioso e no campo político. Contudo, a meu ver, para além das estatísticas e visibilidade no espaço público, para perceber ampliação do pluralismo no interior do campo religioso é preciso olhar, mais atentamente, para as relações entre gerações. Na medida em que diminui a transmissão religiosa intergeracional, e aumentam as famílias multireligiosas, modificam-se as maneiras socialmente disponíveis para lidar com a questão da diversidade religiosa.

Em entrevistas que realizei recentemente, jovens negros na Bahia estranharam o "estranhamento" da pesquisadora que insistia em indagar sobre conflitos na convivência entre pais evangélicos e filhos do candomblé e vice versa. Algo similar aconteceu quando, também recentemente, entrevistei um jovem católico que organiza uma festa de São Sebastião no interior do Rio de Janeiro e em casa convive com a mãe evangélica da Igreja Universal do Reino de Deus, com o pai do candomblé e seus irmãos budistas... Pelas respostas obtidas, pode-se afirmar que, nesses contextos familiares, os laços afetivos se combinam com argumentos que remetem à noção de "diversidade" enfraquecendo 
certas disposições para intolerâncias e sectarismos. "Tem que respeitar", "cada um tem direito de escolher", "é o caminho dele", "não pode ter preconceito", são frases recorrentes que parecem indicar um "impacto prático" da disseminação desse slogan. O que não quer dizer que, tanto no espaço doméstico como no espaço público, não existam situações de conflito em que essas fissuras - ao lado de outras - deixem de ser acionadas. Mas, ainda assim, a categoria "diversidade" permanece no estoque de argumentos socialmente disponível para produzir disputas, convivências e alianças.

Nessa perspectiva, a análise de Birman (2006) sobre a noção de "espiritualidade" nos eventos da ECO-92 e no interior do MIR (Movimento Inter-Religioso), criado na mesma ocasião, é reveladora. Diz o texto:

A noção de espiritualidade, amplamente utilizada na ECO 92 e, após, em todos os desdobramentos das atividades do MIR, possibilitou uma passagem do afro-brasileiro para um novo campo de sentidos. Neste novo campo, os elos do "afro" com a sociedade abrangente não serão mais pensados através de uma cultura nacional que teria uma base africana, fundamentada no candomblé. $\mathrm{O}$ afro se transforma em uma "tradição" entre outras em escala global: a imagem do mundo é construída por meio de uma constelação de "tradições", basicamente religiosas (ainda que algumas vistas como étnicas) que explicam a sua diversidade por um lado e seus conflitos por outro (Birman 2006:202).

E, referindo-se particularmente à vigília inter-religiosa que ocorreu durante a ECO-92, continua a mesma autora: "nesta, as tradições presentes aceitaram o conceito de 'Unidade na Diversidade' e sentiram a importância de acabar com os preconceitos e a incompreensão, levando o MIR para uma esfera mais ampla (..)". Concluindo, Birman destaca: "a diversidade como valor possibilita abrir um novo campo de negociações para a defesa do candomblé, em nome da tolerância e da paz entre os povos" (idem:203).

Certamente a abertura deste "novo campo de negociações" não foi o suficiente para eliminar, nos anos seguintes, sectarismos e certas "guerras santas" (presenciais, radiofônicas ou televisivas). Contudo, tais expedientes não parecem estar mais entre as principais estratégias para recrutar fiéis e lotar certas Igrejas. O que, em certa medida, também está relacionado com as mudanças no espaço público onde a referência aos "direitos humanos" ganha espaço e justifica a emergência de demandas por dispositivos legais para conter discriminações, inclusive religiosas. Nesse contexto, a dimensão religiosa se recoloca justamente na confluência entre os chamados "direitos de cidadania" e os "direitos humanos", antes pertencentes a áreas e a narrativas bem destacadas. 
Com efeito, frutos de disputas e conquistas sociais, cada geração de direitos propiciou historicamente a emergência da outra. A primeira geração se refere aos direitos civis e políticos dos indivíduos. Estes direitos visam garantir a democracia política, o direito à propriedade, a resistência à opressão e a segurança e têm como fundamento a liberdade. A segunda se refere aos direitos econômicos, sociais e culturais. Remetem à educação, cultura, à previdência social, às garantias trabalhistas e liberdade sindical, seu fundamento é a igualdade. Já a terceira, produto de acordos internacionais, refere-se aos direitos difusos. Estes últimos se caracterizam pela consagração de direitos de incidência coletiva e dizem respeito a grupos específicos (mulheres, jovens, negros, migrantes), à garantia de Paz, ao desenvolvimento, ao cuidado com o meio ambiente e ao patrimônio comum da humanidade. Remetem à valorização da diversidade e seu fundamento é a solidariedade.

Cada vez mais acionados no discurso de diferentes atores, os "direitos humanos", como se costuma dizer, "caíram na boca do povo". São os vilóes para grupos e indivíduos que se sentem ameaçados frente a iniciativas "do pessoal dos direitos humanos" consideradas por eles complacentes com "os pobres, os bandidos e os criminosos". Mas, ao mesmo tempo, a referência aos direitos humanos produziu uma espécie de "esperanto" capaz de fornecer uma chave de leitura comum para diferentes segmentos juvenis que levam demandas de distribuição, de reconhecimento ou de participação ao espaço público ${ }^{18}$.

Tais demandas contemplam uma avaliação de suas "condições objetivas" de vida (evocando, sobretudo, mais igualdade) e derivam de vivências subjetivas de discriminação (evocando solidariedade e o direito à diversidade). Em outras palavras, para os jovens mobilizados de hoje, dívidas históricas ("direitos de cidadania") se combinaram com outras tantas ausências advindas dos processos de segregação espacial, discriminação social e degradação ambiental. Nessas circunstâncias, além ser convocado para implantar políticas de redução de desigualdades sócio-econômicas, o Estado é chamado para atuar na área dos "direitos humanos" reconhecendo "atores e territórios vulnerabilizados", criando leis e serviços para a denúncia e a punição de discriminação racial, de violência contra a mulher, de discriminação por orientação sexual e, também, de discriminação religiosa. Assim, a partir de pressões surgidas no espaço público, os governos também são convocados para criar serviços e canais jurídicos para a denúncia de discriminação e perseguição religiosa. Nesse contexto, para além de garantia de "liberdade de culto", o Estado laico é convocado para criar canais de reconhecimento e garantia do "direito à diversidade religiosa".

Trata-se, de fato, de movimentos de mão dupla que produzem novos ruídos, fluxos e confluências entre diferentes dimensões da vida social. Alguns exemplos foram relatados no decorrer desse texto. O Prêmio Hutus, o Acampamento Internacional de Juventude, o Fórum Social Mundial, a Marcha 
das Vadias, gestados no âmbito da chamada "sociedade civil", envolveram grupos religiosos que se fortaleceram ostentando sua "diversidade". O Conselho Nacional de Juventude (Conjuve) e as Conferências Nacionais de Políticas Públicas de Juventude, espaços gestados no âmbito do poder público federal, se legitimaram convocando a "juventude em sua diversidade", inclusive religiosa. Essas iniciativas devem ser compreendidas como parte de um mesmo processo de pressões, negociações e mudanças, no qual a ideia de "diversidade" (cultural e religiosa) - por meio da chave de leitura "direitos humanos" - passou a ser moeda de uso e de troca no espaço público.

Certamente em uma época de inocência perdida já não se trata de apenas celebrar o "respeito à diversidade" (que, em certas circunstâncias, como já foi dito, pode significar apenas preservar, manter distante, isolar grupos e culturas). Assim como não é o bastante afirmar a versão mais atual, politicamente correta, na qual se substitui o verbo "respeitar" por "valorizar". Embora a "valorização da diversidade" traga consigo a ideia de enriquecimento mútuo, e seja mais dinâmica indicando a produção contínua de diferenças, ela também pode ser apenas um "mantra" que, por si, não modifica relações de poder no espaço público. Com efeito, é preciso aproximar esse mantra da área dos direitos, sem esquecer que também nesse caso trata-se de um campo de disputas.

Referindo-se à América Latina, Grimson lembra que:

en la extensa época de formación de los estados nacionales, las narrativas homogeneizantes postulaban que cada país tenía una cultura y una identidad. Este imaginario estaba vinculado a una concepción del desarrollo, que sólo podía desplegarse evitando los obstáculos culturales. Esos obstáculos eran las alteridades "internas" que no adoptaban, siempre y para todo, los valores productivistas como único criterio de constitución e ilusión comunitaria (...) Después de ese nacionalismo homogeneizante, sin embargo, se impuso una nueva concepción, bastante extendida en la región, que acompañó las nuevas políticas neoliberales con el multiculturalismo, desde pequeñas insinuaciones en algunos países, hasta reformas constitucionales en otros. La construcción clásica de hegemonía, que incluía alguna ilusión de ciudadanía universal con un relato cultural homogenizador, se había roto. Entrábamos a la época de las identidades múltiples, fragmentarias, particulares, muy útiles al proyecto de deconstruir los estados como un todo. Si el primer modelo le otorgaba a veces a la nación y otras a la clase una prelavencia supuestamente objetiva para el cambio social, el neoliberal y posmoderno le otorgaba el predominio a la multiplicidad (2011:7). 
A partir dessa contextualização histórica, o autor afirma que o

reconocimiento de diferencias culturales no tiene un valor éticopolítico esencial, sino que su sentido depende de la situación social. El problema surge cuando distintos sectores entablan una disputa sobre las valoraciones y consecuencias de unas diferencias que se consideran autoevidentes. Sin embargo, la diversidad no debe comprenderse como un mapa esencializado y trascendente de diferencias, sino como un proceso abierto y dinámico, un proceso relacional vinculado a desigualdades y relaciones de poder (idem:13).

O mesmo pode ser dito sobre a questão da diversidade religiosa que também se configura em um processo relacional. Se é verdade que hoje tanto as grandes religiões mundiais quanto as novas religiosidades têm sido circunstancialmente impelidas a se apresentar no espaço público por meio de mensagens e ações contra sectarismos e fundamentalismos e em defesa da paz, dos direitos humanos e da sustentabilidade ambiental, isto não parece significar qualquer ameaça de "religiogização da política". Gestadas na sociedade civil, tais iniciativas só tem sentido na medida em que partem da afirmação do caráter laico do Estado. No Brasil é, justamente, no reconhecimento do caráter republicano e secular do Estado que reside tanto a possibilidade de que the seja atribuído o papel de "guardião de nossa diversidade", quanto a possibilidade de que os posicionamentos de diversos grupos religiosos - ao lado de outros atores políticos - possam incrementar dinâmicas e disputas no espaço público.

Por outro lado, "a politização de categorias religiosas", por parte de determinados segmentos juvenis que declaram "lutar por direitos", não depende só da vontade do observador, dos ideais republicanos dos cientistas sociais ou do que foi escrito por autores clássicos de nossas disciplinas. Aos antropólogos e aos sociólogos da religião de hoje cabe, por obrigação profissional, compreender tais deslocamentos e confluências como parte da realidade que se quer conhecer.

No contexto, bem delimitado deste artigo, pode-se dizer que certas apropriações da noção de "diversidade religiosa" e de "direitos humanos" produzem efeitos de renovação do fazer político e justificam presenças de jovens religiosamente motivados nos embates que se dão no espaço público. Trata-se agora de dialogar e se reapropriar do legado da literatura sociológica e antropológica que identificou clássicos pares de oposição (sagrado/profano; religioso/civil; público/privado; individual/coletivo), buscando identificar os fluxos comunicacionais entre esses polos. Bem como, trata-se também de buscar outras categorias e costuras explicativas que nos aproximem um pouco mais da experiência social dos jovens desta geração. 


\section{Referências Bibliográficas}

ALMEIDA, Ronaldo. (2006), "A expansão Pentecostal: circulação e flexibilidade". In: F. Teixeira e R. Menezes (orgs.). As religiões no Brasil. Continuidades e Rupturas. Petrópolis: Vozes.

BERGER, Peter. (2001), "A Dessecularização do mundo: uma visão global". Religião e Sociedade, v. 21, n. 1: 9-23.

BIRMAN, Patricia. (2006), "Percursos afro e conexões sociais: negritude, pentecostalismo e espiritualidades". In: F. Teixeira e R. Menezes. As religiões no Brasil. Continuidades e Rupturas. Petrópolis: Vozes.

BOURDIEU, Pierre. (2004), "A crença dos sociólogos e os sociólogos da crença". Coisas Ditas. São Paulo: Brasiliense.

CALDERÓN, F. e LECHNER, N. (1998), Mas allá Del Estado, mas allá Del Mercado: la democracia. La Paz: Plural.

CARDOSO DE OLIVEIRA, Roberto. (1988), "A categoria (Des)Ordem e a Pós-modernidade na Antropologia". Anuário Antropológico, n. 86. Rio de Janeiro: Tempo Brasileiro.

FISCHER, Nilton Bueno; CORREA, Ana Maria dos Santos; AMARAL, Márcio. (2007), "Acampamento Intercontinental da Juventude". In: A. L. S. Souto e P. Pontual (coords.). Juventude e Integração Sul-Americana: caracterização de situações-tipo e organizações juvenis. Rio de Janeiro: Ibase/Polis. Disponível em http://pt.scribd.com/ibase_rede/d/51823783-Relatorio-Juventude-Brasil. Consultado em 10/01/2008.

CAMURÇA, Marcelo Ayres \& TAVARES, Fátima Regina Gomes. (2004), “Juventudes' e Religião no Brasil: uma revisão bibliográfica". Numen, v.7, n¹: 11-46.

DEBATES DO NER. (2001), Religião, Política e Ciências Sociais. Ano 2, n. 2. Porto Alegre: UFGRS. GIDDENS, Anthony. (1990), As consequências da Modernidade. São Paulo: Unesp.

GIUMBELLI, Emerson e SÁ CARNEIRO, Sandra. (2004), "O ensino religioso no estado do Rio de Janeiro: registros e controvérsias”. Comunicações do Iser, n. 60. Rio de Janeiro: Iser.

GIUMBELLI, Emerson. (2006), "Minorias Religiosas". In: F. Teixeira e R. Menezes (orgs.). As religiões no Brasil. Continuidades e Rupturas. Petrópolis: Vozes.

GRIMSON, Alejandro. (2011), "La polisemia de la diversidad y sus políticas públicas". Encontro da Rede de Intelectuais trabalhadores da Cultura. Montevideo: UNESCO, mimeo.

MAFRA, Clara. (2011), "A arma da cultura e os universalismos parciais". Mana, 17(3): 607-624.

MENDONÇA, A.G. (2006), "Evangélicos e Pentecostais: Um campo religioso em ebuliçãa”. In: F. Teixeira e R. Menezes (orgs.). As religiões no Brasil. Continuidades e Rupturas. Petrópolis: Vozes.

NOVAES, Regina Reyes. (1994), "Religião e política: sincretismos entre alunos de Ciências Sociais". Comunicações do ISER, no-45: 62-74. Sociedade, 20(1): 65-92.

(1999), "Ouvir para crer: os Racionais e a fé na palavra". Religião e

(2003), "Errantes do novo milênio: salmos e versículos bíblicos no espaço público”. In: P. Birman (org.). Religião e Espaço Público. Brasília/São Paulo: CNPq/PRONEX/Attar Editorial.

PACE, Enzo. (1997), "Religião e Globalização". In: A. Oro e C. Steil (orgs.). Religião e Globalização. Petrópolis: Vozes.

RODRIGUES, S. (2012), "Jovens, experiência do sagrado e pertencimento religioso: um olhar sobre a literatura". No prelo.

PIERUCCI, A. F. (1997), "Interesses religiosos dos sociólogos da religião". In: A. Oro e C. Steil (orgs.). Globalização e Religião. Petrópolis: Vozes.

PITREZ, Maria Claudia. (2012), "O Feriado de São Jorge e o Dia do Evangélico: A institucionalização de datas religiosas nos calendários cívicos do Rio de Janeiro". Cadernos do NER, no prelo.

SANCHIS, Pierre. (2001), "Religião, religiões... Alguns problemas do sincretismo no campo religioso brasileiro". Fiéis e Cidadãos. Rio de Janeiro: Eduerj. 


\section{Notas}

1 As ideias contidas neste trabalho foram apresentadas no Encontro Anual da ANPOCS de 2011, em Mesa Redonda organizada por Cristina Pompa, a quem agradeço o convite e a oportunidade de instigante discussão acadêmica com Paula Montero e Patrícia Birman. Para Patrícia registro também um particular e afetuoso agradecimento pelas contribuições e leitura crítica deste artigo.

2 Desta vez participei de uma pesquisa coordenada pelo NER da UFRGS, envolvendo várias universidades brasileiras. Ver DEBATES DO NER (2001). Para um cuidadoso balanço destas pesquisas, ver Camurça e Tavares (2004).

3 Sobre as demais características do movimento hip hop, ver Novaes (1999 e 2003). Nos últimos anos, como estilo musical, o rap está presente em outros espaços e entre outros grupos sociais. Mas, ainda, se vê e é visto como a expressão maior da chamada "cultura de periferia".

4 A mensagem é praticamente a mesma, mas as músicas não são necessariamente parecidas. $\mathrm{O}$ rap gospel tem influências estéticas do rap alternativo, do $R \& B$, do dirty south, do rock e até do gangsta rap.

5 Recentemente entrevistei uma jovem negra, criada por mãe católica, que relatou como, buscando pela internet, iniciou-se em praticas esotéricas de tradição lusitana. Depois de um tempo de buscas e experimentações religiosas virtuais, hoje ela está ligada a um espaço local liderado por um "mestre" baiano, onde se "faz um trabalho" de aproximação entre figuras míticas e princípios da "bruxaria", ligada ao esoterismo europeu, da ancestralidade dos orixás. Verifica-se aí uma possibilidade de sincretismo "nova era".

6 Mendonça (2006) menciona o "cansaço religioso" como causa que levaria fiéis protestantes a enfraquecerem vínculos institucionais.

7 Almeida (2006:112/3) chamou a atenção para a "circulação de ideias e práticas evangélicas pra além das fronteiras institucionais" e para flexibilidade do vínculo institucional para uma população flutuante que "se serve" da religiosidade pentecostal. O autor caracterizou um "pentecostalismo de serviços", uma espécie de "magia de matriz cristã", que abre a possibilidade do pentecostalismo aparecer como segunda religião e que, também, introduz certa tolerância no interior das igrejas pentecostais.

8 Esta expressão foi cunhada a partir do uso corrente de "remédio genérico".

9 Para uma sugestiva análise sobre "minorias religiosas" ver Giumbelli (2006).

${ }^{10}$ Para aprofundar o assunto deveríamos levar em conta os contextos e as estratégias de apresentação social em jogo quando alguém responde "qual é a sua religião?".

${ }^{11}$ As demais categorias correspondentes foram: personalidade hip hop; produtor musical; melhor música; melhor álbum; melhor DJ; melhor demo; veículo de comunicação; gravadora ou selo; melhor vídeo clip; melhor grupo feminino; revelação do ano; melhor grupo. Após dez anos o prêmio Hutus deixou de existir em 2011. Em 2007 o Ministério da Cultura criou o Premio Hip Hop Brasil.

${ }^{12}$ Ver documento oficial de fundação do Fórum Social Mundial citado por Fischer et alli (2007).

${ }_{13}$ Naquele ano de 2003, o Fórum Social Mundial, por vezes definido como "Woodstock da Cidadania", realizado em Porto Alegre, entre 23 e 28 de janeiro, reuniu 100 mil pessoas e mais de 5 mil organizações não-governamentais de 156 países. Através de painéis, conferências, workshops, testemunhos, atividades culturais e diálogos informais. A mídia enviou 4.094 jornalistas de mais de 51 países para divulgar o Fórum ao redor do mundo.

${ }^{14}$ Ver Fischer et alli (2007) onde os autores analisam conflitos entre diferentes grupos de jovens; entre acampados e a polícia da cidade de Porto Alegre; entre os organizadores e grande mídia.

15 O Conjuve foi criado em 2005 e reúne $1 / 3$ de representantes do poder público e $2 / 3$ de grupos, movimentos e redes de jovens ou que trabalham com jovens.

${ }^{16}$ Ver Rodrigues (2012) para uma sugestiva ideia sobre um possível "efeito Conjuve" no campo das juventudes religiosas. A autora lembra que, em um primeiro momento, o reconhecimento do engajamento político justificou a presença de jovens religiosos no Conjuve (por exemplo, os jovens 
da Pastoral da Juventude e da Aliança Bíblica Universitária do Brasil). Depois, uma vez definidas "cadeiras" para candidaturas de "juventudes religiosas", outras organizações juvenis religiosas passam a disputar essas vagas, pelo simples fato de aglutinarem jovens, independentemente do tipo de ações que desenvolvem no campo social ou no espaço público. Resta analisar quais as repercussões desta participação seja no próprio Conjuve, seja nos espaços religiosos de onde vêm estes jovens.

${ }^{17}$ Segundo consulta na internet: "A Comunidade Betel do Rio de Janeiro, filiada às Igrejas da Comunidade Metropolitana (ICM), é uma Igreja Inclusiva, onde LÉSBICAS, GAYS, BISSEXUAIS E TRANSGÊNEROS são bem vindos e não discriminados pela sua orientação sexual. Nós afirmamos que A BÍBLIA NÃO CONDENA A HOMOSSEXUALIDADE e que 'Deus não faz acepção de pessoas' (At 10.34). A Comunidade Betel é também uma Igreja que rejeita o fundamentalismo bíblico, o legalismo cristão e doutrinas religiosas opressoras como a Teologia da Prosperidade. Quer saber mais sobre nós, nossas visões e crenças? www.betelrj.com". Consultado em 30 de maio de 2012.

${ }^{18}$ A consigna da II Conferência Nacional de Políticas Públicas de Juventude, realizada em Brasília em dezembro de 2011, foi "Conquistar direitos e desenvolver o Brasil". Os eixos do documento-base foram: 1) Direito ao desenvolvimento integral (Trabalho, Educação, Cultura e Comunicação); 2) Direito ao território (Povos tradicionais, Jovens Rurais, Direito à Cidade, ao Transporte, ao Meio ambiente); 3) Direito à experimentação e qualidade de vida (saúde, esporte, lazer e tempo livre); 4) Direito à diversidade e vida segura (segurança, diversidade e direitos humanos); e 5) Direito à participação. A religião aparece no eixo 4 entre as diversidades sujeitas a discriminações e que suscitam políticas públicas específicas.

Recebido em dezembro de 2011

Aprovado em março de 2012

Regina R. Novaes (Novaes-regina@uol.com.br) Antropóloga, com graduação em Ciências Sociais no IFCS-UFRJ; mestrado em Antropologia Social pelo Museu Nacional/UFRJ e doutorado em Ciências Humanas pela USP. Foi professora do IFCS-UFRJ, atualmente é pesquisadora do CNPq, desenvolvendo o Projeto Juventude, Religião e Política e, também, é Consultora da UNESCO para a Agenda Juventude. 


\section{Resumo:}

\section{Juventude, religião e espaço público: exemplos "bons para pensar" tempos e sinais}

Com o objetivo de refletir sobre determinadas confluências entre as dimensões políticas e religiosas da vida social contemporânea, o artigo retoma informações de pesquisas realizadas pela autora entre segmentos de jovens brasileiros que - de maneiras diversas - se apresentam no espaço público por meio referências, valores ou identidades religiosas. Sem minimizar o hiato existente entre as retóricas e as ações práticas do poder público e reconhecendo sobreposições identitárias nas estratégias de apresentação social, no âmbito da chamada sociedade civil, o artigo discute algumas das (re)apropriações da noção de direitos humanos e diversidade cultural (e religiosa) entre jovens que hoje se movem em espaços da ciência, da cultura e da política, suscitando reinvenção de conceitos e novas costuras explicativas.

Palavras-chave: geração, diversidade religiosa, política.

\section{Abstract:}

Youth, Religion and public space: examples "good to think" times and signs

In order to reflect on certain confluences between religious and political dimensions of contemporary social life, the article incorporates information from researches conducted by the author between segments of young Brazilians that - in different ways - project yourselfs in public space through religious references, values or identities. Without minimizing the gap between the rhetoric and the practicalities of government and recognizing identity overlap in the strategies of social presentation in the context of the civil society, the article discusses some of the (re)appropriations of the concept of human rights and cultural (and religious) diversity among young people wich moves today in space of science, culture and politics, inspiring reinvention of new concepts and explanatory seams.

Keywords: generation, religious diversity, politics. 